\title{
Dynamic Impact of Interest Rate Policy on Real Estate Market
}

\author{
Jianghong Zhang \\ College of Economics and Management, Sichuan Agriculture University \\ 211 Huimin Road, Wenjiang District, Chengdu 611130, China \\ E-mail: 66884597@qq.com \\ Wenkuan Chen (Corresponding author) \\ College of Economics and Management, Sichuan Agriculture University \\ 211 Huimin Road, Wenjiang District, Chengdu 611130, China \\ E-mail: cwk9889@yahoo.com.cn
}

$\begin{array}{lcc}\text { Received: May 28, 2011 } & \text { Accepted: June 28, } 2011 \quad \text { Published: October 1, } 2011 \\ \text { doi:10.5539/ass.v7n10p188 } & \text { URL: http://dx.doi.org/10.5539/ass.v7n10p188 }\end{array}$

Sponsoring information: The research is financed by Subject-Scientific and Technological Support Program in rural areas No.2010N20105

\begin{abstract}
The purpose of this paper is to analyze the dynamic impact of Interest Rate Policy on the Real Estate Market. In this paper we constructed a vector autoregression (VAR) model using five indicators and analyzed the response of the real estate market to the impulse of interest rate policy based on the monthly data from January 2003 to September 2010 in China. The results show that the Central Bank Reserve Ratio has a negative impact on the real estate market from a long-term perspective; and the lags of interest rate policy effect is longer, while action period is shorter from a short-term perspective. So we consider that the Interest Rate Policy does not play a significant role in the regulation of real estate market in this paper.
\end{abstract}

Keywords: Real estate market, Interest rate policy, Dynamic impact, Vector autoregression model

\section{Introduction}

In recent years, the industry of real estate has developed rapidly in China. The industry of real estate has become the lifeblood of the economy in China. "Real estate industry is very important. It is pulling more than 50 industries, from the upstream industry such as iron, steel and building materials to the downstream industry such as household appliances, curtains and even ceramic tile. So it has a very strong pulling power." Jingyuan Yao, the chief economist from the National Bureau of Statistics said (2009). Nowadays, facing the excessive investment on real estate and soaring housing prices, the government has issued a series of real estate control policies to hold back the rapid increase of housing prices since 2010. The booming housing price has been moderately curbed and the real estate speculation has been strongly hit under the micro-control policy.

Interest rate policy is one of the main tools of current real estate macro-control monetary policy. On January 12th, 2010, the People's Bank of China had made a decision to raise deposit-taking financial institutions of RMB deposit reserve ratio by $0.5 \%$ from February 25th, 2010. The central bank has raised the reserve ratio four times from November, 2010. The one-year benchmark lending rate for financial institutions was raised to $5.56 \%$ by $0.25 \%$, the more than five-year benchmark lending rate was raised to $6.14 \%$ by $0.2 \%$, the more than five-year housing fund rate was raised to $4.05 \%$ by $0.18 \%$. In order to curb the excessive growth of housing prices, the government uses the interest rate policy to affect the real estate investment and real estate needs.

However, how does interest rate policy, which is the main instrument in the current monetary policy instruments, act on the real estate market and impact the real estate market by the central bank's reserve and interest rate adjustment after relaxing China's controlled economy? Embarked on this analysis, this article will establish VAR and VEC models to study dynamic impact of interest rate change on the real estate market both in the long-term 
and short-term based on the monthly data from January 2003 to September 2010 in China. Zhong (2009).

Up to now, the related literatures on the real estate market are very affluent. But they mainly focus on the basic theory research or definition study based on the annual data for the overall trend analysis, lacking the in-depth research based on monthly data. And loads of the current research only answer the relationship between the interest rate alteration and the housing price fluctuate, or argue that whether the interest rate policy play a significant role in controlling the real estate market. So we decide to collect the objective monthly data from January 2003 to September 2010 in China for the empirical research by consulting the relative research methods and ideas from home and abroad. In this paper we analyzed the impact of interest rate policy on the real estate market both in long-term and in short-term and observed the action process in the real estate market. The results of this paper can provide an empirical basis for the further scientific and reasonable interest rate adjustment in real estate.

\section{Methodology}

The structural approach to simultaneous equations modeling uses economic theory to describe the relationships between several variables of interest. The resulting model is then estimated and used to test the empirical relevance of the theory.

Unfortunately, economic theory is often not rich enough to provide a tight specification of the dynamic relationship among variables. Furthermore, estimation and inference are complicated by the fact that endogenous variables may appear on both the left and right sides of the equations.

These problems lead to alternative, non-structural, approaches to modeling the relationship between several variables. Here we describe the estimation and analysis of vector autoregression.

The vector autoregression (VAR) is commonly used for forecasting systems of interrelated time series and for analyzing the dynamic impact of random disturbances on the system of variables. The VAR approach sidesteps the need for structural modeling by modeling every endogenous variable in the system as a function of the lagged values of all of the endogenous variables in the system. The mathematical form of a VAR is

$$
\mathrm{Y}_{t}=A_{1} \mathrm{Y}_{t-1}+\cdots A_{d} \mathrm{Y}_{t-d}+B X_{t}+\varepsilon_{\mathrm{t}} \quad t=1 \cdots \mathrm{T}
$$

where $Y_{t}$ is a $k$ vector of endogenous variables, $X_{t}$ is a $d$ vector of exogenous variables, and $B$ are matrices of coefficients to be estimated, and $\varepsilon_{\mathrm{t}}$ is a vector of innovations that may be contemporaneously correlated with each other but are uncorrelated with their own lagged values and uncorrelated with all of the right-hand side variables. Doan (2007).

\section{Empirical analysis based on China real estate market}

\subsection{Data}

The national monthly sample data, from January 2003 to September 2010, was collected from the National Bureau of Statistics website, the People's Bank of China website, Eastern wealth network and Leshan City housing fund management center. The software of Eviews6.0 was used for statistical analysis in this paper.

Considering the pertinence to the real estate market, we selected three indicators from the interest rate policy to reflect the situation of interest rate policy: the Central Bank reserve ratio, 1-year benchmark lending rate and more than 5-year benchmark lending rate. From the real estate market, we selected the newly started acreage of real estate index to reflect the supply situation and selected the acreage of property sales index to reflect the needs of the real estate market conditions. Above two real estate indicators can preferably reflect supply and demand in the real estate market, because they eliminate the price interference which other indicators, such as investment, sales, can't ruled out.

In order to eliminate the impact of inflation on interest rate index, we get real interest rates index from the differences between interest rates and the inflation rate, which stands for the CPI growth rate. Meanwhile, form the data, we find that real estate data has obvious seasonal fluctuations. In order to eliminate the seasonal effects, we deal with this problem using the standard X12 seasonal adjustment Yi (2008). The interest rate policy and the real estate market index system are in Table 1. (Note 1)

\subsection{Model estimation on interest rate policy and real estate demand}

\subsubsection{Model estimation of VAR}

Firstly, we analyze the initial data and their first-order differences to test for the stability of the Granger causality relationships, using the (ADF) and Phillips-Perron (PP) technique. Gao (2009). From the results displayed in the table 2 , We could find that the test of all time-series variables reject stability at the $1 \%$ confidence level, but their 
first-order difference serial data which we called first-order fractional integration list, I(1), receive stability. (Note 2)

For that composing VAR model need stable time-series variables, by the test from last section, we use the first-order difference lists of the Central Bank reserve ratio, 1-year benchmark lending rate, more than 5-year benchmark lending rate and the acreage of property sales to construct the VAR model. Table 3 shows the best lagged value under Akaike Information Criterion(AIC) is 12, but it is 1 under Schwarz Criterion(SC) at the level of $5 \%$. We have to do a likelihood ratio (LR) test to decide the final lagged value, for the different lagged values between AIC and SC. (Note 3)

We do the LR test on the assumption that $\mathrm{H}_{0}$ : The elements in the coefficient matrix $\mathrm{A} 2$ are all zeros, while the lagged value was two.

$$
\mathrm{LR}=-2(\log \mathrm{L} 1-\log \mathrm{L} 2)=-2 *(-553.2533-(-533.0014))=40.5038>(25)=34.382
$$

The statistical index is distinctness, the coefficient matrix A2 contains at least one non-zero element. Therefore, we reject the initial assumption, which means the final lagged value is 2-step.

In order to confirm the presence of cointegrating relationships among the acreage of property sales and other interest rate policy variables. We use Johansen test to the 2-step VAR equations. Johansen (1991, 1995). The results of table 4 appear that the cointegrating relationships exist among the variables at $5 \%$ level. (Note 4 )

\subsubsection{Model estimation of VEC}

Next, we do the block exogeneity test. It shows in table 5 that the variables of Central Bank reserve ratio, 1-year benchmark lending rate and more than 5-year benchmark lending rate have been the endogenous variables to the acreage of property sales index for their combined probability 0.0073 less than the critical value 0.05 . (Note 5)

For further research of the short-term relationship between the acreage of property sales index and other interest rate policy indexes, we modify it by building a vector error correction (VEC) model. From the VEC model we find that: in the shot-term, under the 5\% level, 1 unit undulate of the acreage of property sales index that lagged one month will cause 0.0028 unit reduction to the temporal acreage of property sales, 1 unit undulate of the Central Bank reserve ratio index that lagged one month will cause 1.851 unit increase to the temporal acreage of property sales, 1 unit undulate of the 1 -year benchmark lending rate index that lagged one month will cause 65.453 unit reduction to the temporal acreage of property sales, 1 unit undulate of more than 5-year benchmark lending rate index that lagged one month will cause 30.55 unit reduction to the temporal acreage of property sales, and the others have little evidence on the temporal acreage of property sales.

\subsubsection{Analysis of impulse response function}

To describe the dynamic impact of real estate demand variable on the impulsion of certain interest rate policy index, we use impulse response function to picture the response of VAR model to the shock of certain endogenous variable in this paper.

From the figure 1 we can conclude that : Firstly, when we make the positive impulse to the central bank reserve ratio, the response of the acreage of property sales will decline at the beginning, and then recover from the second period till steady negative impact at the sixth period. Secondly, when we make the positive impulse to the 1 -year benchmark lending rate, the response of the acreage of property sales will not fluctuate. Finally, when we make the positive impulse to more than 5-year benchmark lending rate, the response of the acreage of property sales will mount up, and get peak value at the third period, till that the impact disappear at the fourth period. (Note 6)

\section{3 model estimation on interest rate policy and real estate supply}

As the same of the analysis for the real estate demand, we do the model estimation on interest rate policy and real estate supply.

Firstly, from the variable tests to the time-series vectors, we obtain the following results: First for the stability test we use the first-order differences of all initial data to construct VAR model; Second for the lagged value test we select lagged 2-step to the VAR model; Third for the presence of cointegrating relationships test we know that the cointegrating relationships exist among the data at critical value 0.05 ; Finally for the block exogeneity test we can see that only the Central Bank reserve ratio index is the endogenous variable to the newly started acreage of real estate.

Next, from the VEC model we find that: in the shot-term, under the 5\% level, 1 unit undulate of the newly started acreage of real estate index that lagged one month will cause 0.236 unit reduction to the temporal newly 
started acreage of real estate, 1 unit undulate of the Central Bank reserve ratio index that lagged one month will cause 193.2795 unit reduction to the temporal newly started acreage of real estate, and the others have little evidence on the temporal newly started acreage of real estate.

Finally, with the analysis of impulse response function, we conclude that: When we make the positive impulse to the central bank reserve ratio, the response of newly started acreage of real estate will decline firstly, and get low-water mark at second period, till that the impact disappear at the sixth period. (Note 7)

\section{Conclusions and Policy Suggestions}

\subsection{Conclusions about the Dynamic Impact of Interest Rate Policy on China's Real Estate Market}

4.1.1 From a long-term perspective, the reserve ratio has negative impact on the real estate market

At the sight of long-term stable relationship, the Central Bank reserve ratio has a negative impact on the real estate market, which means that the Central Bank reserve ratio affect both the real estate market demand and supply negatively. The continually rising of reserve ratio compressed the market liquidity, indirectly increased the difficulty of investment and financing of real estate market.

\subsubsection{From a short-term perspective, lags of interest policy effect is longer, while action period shorter}

In the short term, using VEC model and impulse response function analysis, we can see that acreage of property sales will descend and newly started acreage of real estate will decrease if reserve ratio is exerted by positive impact. Both are affected the greatest in the second phase(decreasing to the minimum), then pick up turbulently, and in the sixth phase and forth will have a steadily negative influence for the acreage of property sales, but have no influence for the newly started acreage of real estate, this is the same with the long-term conclusion. The long lags as well as the short action period reduce the effect of the interest policy for the real estate market

4.1.3 Interest rate policy does not play a significant role in the real estate market regulation

From the above analysis, we can see that neither the acreage of property sales nor the newly started acreage of real estate react greatly to the interest rate policy. To some extent, it reflected that the micro-control of interest rate policy played a weak role in the real estate market. This phenomenon is corresponding with the status quo of Chinese official interest rate policy which has hysteresis. Although the real estate industry is capital-intensive, due to the lagged interest rate policy, there is no intense reaction of real estate investment to interest rate change. Together with that Chinese current control rates policy which does not change with the market regulation, the leverage of itself cannot be fully displayed. Therefore, it is easy to understand why the government directly make Vigorous policy interventions in the real estate market. That is because as the government's most favorable interest rate tool, the rate policy cannot effectively regulate the real estate market, so the government had to regulate the real estate industry using administrative, legal, credit policy and so forth.

\subsection{Policy Suggestions about Chinese Real Estate Market}

Based on the conclusions, The government should suppress the real estate market from overheating, in view of the limited interest rate policy, and according to Chinese actual conditions, we can take some macro-control measures in the real estate industry: (1) Enhancing estate related credit policy, Strictly restrict the credit limit and credit audit conditions, control domestic real estate loans and speculative housing loan, regulating the housing finance business (2) Strengthening the regulation of land supply process, monopolise the primary land market and increase land reserve quantities, practically supervise land market trading behavior. Perfecting relevant laws and regulations to regulate the government behavior (3) Fully exerting administrative control measures to make sure a coordinated development between the planning of urban real estate industry and other entity economies.

\section{References}

Doan, T.A. (2007). User's guide: RATS, version 7. Evanston, IL: Estimate.

Gao, TieMei. (2009). Econometric analysis method and modeling--EViews application and examples. Tsinghua university press, March.

Johansen, S. (1991). Estimation and hypothesis testing of co integration vectors in Gaussian vector autoregressive models. Econometrical, 59(6):1551-1580. [Online] Available: http://www.cnki.com.cn/Article/CJFDTotal-JJSH200906017.htm

Johansen, S. (1995). Likelihood-based inference in co integrated vector autoregressive models. Oxford: Oxford University Press. [Online] Available: http://www.cnki.com.cn/Article/CJFDTotal-ANHE200924252.htm

Li, Muzi. (2009). China real estate: farewell "carriage era". [Online] Available: http://zqrb.ccstock.cn/html/2009-11/28/content_187249.htm (November 28, 2009) 
Xu, Guoxiang. (2009). Financial Statistics. Gezhi book concern.

Yi, Danhui. (2008). Data analysis and EViews application. Chinese People University press. [Online] Available: http://www.cnki.com.cn/Article/CJFDTOTAL-LQJS201002004.htm

Zhong, TingJun. (2009). Some Suggestions of the Academic Research Method about Real Estate in China. Economic Journal of Hubei province college, 7(5): 38-41. [Online] Available: http://www.cnki.com.cn/Article/CJFDTOTAL-FZSL201101034.htm

\section{Notes}

Note 1 . This is an index system which reflects the fact of interest rate policy and the real estate market.

Note 2. This is a test for the stability of all time-series variables.

Note 3. This is a test for the lagged value of VAR equations.

Note 4 . This is a test for the presence of cointegrating relationships among variables.

Note 5. This is a test for the endogenous variable of the VAR model.

Note 6 . This is a response trade for the acreage of property sales index to one variable

Note 7. This is a response trade for the newly started acreage of real estate index to one variable

Table 1. Index system of Interest Rate Policy and Real Estate Market

\begin{tabular}{cc}
\hline Item & Indicator \\
\hline \multirow{2}{*}{ Interest Rate Policy } & Central Bank Reserve Ratio (Re-c) \\
& 1-year Benchmark Lending Rate (Rate1-c) \\
& More than 5-year Benchmark Lending Rate (Rate2-c) \\
\hline \multirow{2}{*}{ Real Estate Market } & Newly Started Acreage of Real Estate (Ins-sa) \\
& Acreage of Property Sales (Hs-sa) \\
\hline
\end{tabular}

In table 1, there are three indicators which reflect the fact of interest rate policy, and two indicators which reflect the fact of the real estate market.

Table 2. Test for Stability

\begin{tabular}{|c|c|c|c|c|c|c|c|}
\hline \multirow{2}{*}{ Variable } & \multicolumn{3}{|c|}{ Initial data } & \multicolumn{3}{c|}{ First-order difference list } & \multirow{2}{*}{ Result } \\
\cline { 2 - 7 } & $\mathrm{T}$ & $\mathrm{P}$ & $1 \%$ & $\mathrm{~T}$ & $\mathrm{P}$ & $1 \%$ & \\
\hline Hs-sa & -2.6329 & 0.0901 & -3.5030 & -10.6640 & 0.0000 & -3.5144 & $\mathrm{I}(1)$ \\
\hline Isn-sa & -0.6327 & 0.8570 & -3.5030 & -16.0095 & 0.0001 & -3.5144 & $\mathrm{I}(1)$ \\
\hline Re-c & -0.5326 & 0.8789 & -3.5030 & -9.0048 & 0.0000 & -3.5144 & $\mathrm{I}(1)$ \\
\hline Rate1-c & -1.7606 & 0.3977 & -3.5030 & -8.3285 & 0.0000 & -3.5144 & $\mathrm{I}(1)$ \\
\hline Rate2-c & -1.7196 & 0.4181 & -3.5030 & -8.1648 & 0.0000 & -3.5144 & $\mathrm{I}(1)$ \\
\hline
\end{tabular}

In table 2 , we can see $\mathrm{P}$ test in the first-order difference list, it reject $\mathrm{P}$ test. 
Table 3. Test for Lagged Value

\begin{tabular}{ccccccc}
\hline Lag & LogL & LR & FPE & AIC & SC & HQ \\
\hline 0 & -1023.056 & NA & 72744.81 & 25.38409 & 25.53190 & 25.44339 \\
1 & -553.2533 & 870.0044 & $1.237744^{*}$ & 14.40132 & $15.28815^{*}$ & $14.75713^{*}$ \\
2 & -533.0014 & 35.00341 & 1.401592 & 14.51855 & 16.14441 & 15.17087 \\
3 & -504.4075 & 45.89138 & 1.305700 & 14.42981 & 16.79470 & 15.37864 \\
4 & -488.1719 & 24.05275 & 1.677631 & 14.64622 & 17.75013 & 15.89155 \\
5 & -476.4421 & 15.92930 & 2.464764 & 14.97388 & 18.81682 & 16.51572 \\
6 & -455.6234 & 25.70207 & 2.983078 & 15.07712 & 19.65909 & 16.91547 \\
7 & -438.8958 & 18.58628 & 4.158295 & 15.28138 & 20.60238 & 17.41623 \\
8 & -424.0520 & 14.66052 & 6.402847 & 15.53215 & 21.59217 & 17.96351 \\
9 & -399.3885 & 21.31411 & 8.299999 & 15.54046 & 22.33951 & 18.26833 \\
10 & -363.8979 & 26.28937 & 9.059109 & 15.28143 & 22.81951 & 18.30581 \\
11 & -329.2068 & 21.41423 & 11.52714 & 15.04214 & 23.31925 & 18.36303 \\
12 & -227.5137 & $50.21882^{*}$ & 3.416824 & $13.14849 *$ & 22.16462 & 16.76588 \\
\hline
\end{tabular}

In table 3, AIC rule choose 12, but SC rule choose 1 for the least.

Table 4. Test for Presence of Cointegrating Relationships

\begin{tabular}{ccccc}
\hline $\begin{array}{c}\text { Hypothesized } \\
\text { No. of CE(s) }\end{array}$ & Eigenvalue & $\begin{array}{c}\text { Trace } \\
\text { Statistic }\end{array}$ & Critical Value 0.05 & Prob.** \\
\hline None ${ }^{*}$ & 0.380483 & 85.41985 & 69.81889 & 0.0017 \\
At most 1 & 0.230450 & 42.32653 & 47.85613 & 0.1498 \\
At most 2 & 0.104577 & 18.75105 & 29.79707 & 0.5109 \\
At most 3 & 0.090195 & 8.809728 & 15.49471 & 0.3833 \\
\hline
\end{tabular}

In table 4 , we can see form last arrange: $0.0017<0.05$ indicate that None $*$ reject the hypothesizer, so the cointegrating relationship exists among the variables.

Table 5. Test for Exogeneity

\begin{tabular}{cccc}
\hline Excluded & Chi-sq & df & Prob. \\
\hline RE-C & 10.51041 & 2 & 0.0052 \\
RATE1-C & 7.824483 & 2 & 0.0200 \\
RATE2-C & 7.657799 & 2 & 0.0217 \\
All & 20.94190 & 8 & 0.0073 \\
\hline
\end{tabular}

In table 5, we can see form last arrange: $0.073<0.05$, all reject the hypothesizer, so all of the variables are endogenous variables to the VAR model. 
Response to Cholesky One S.D. Innovations
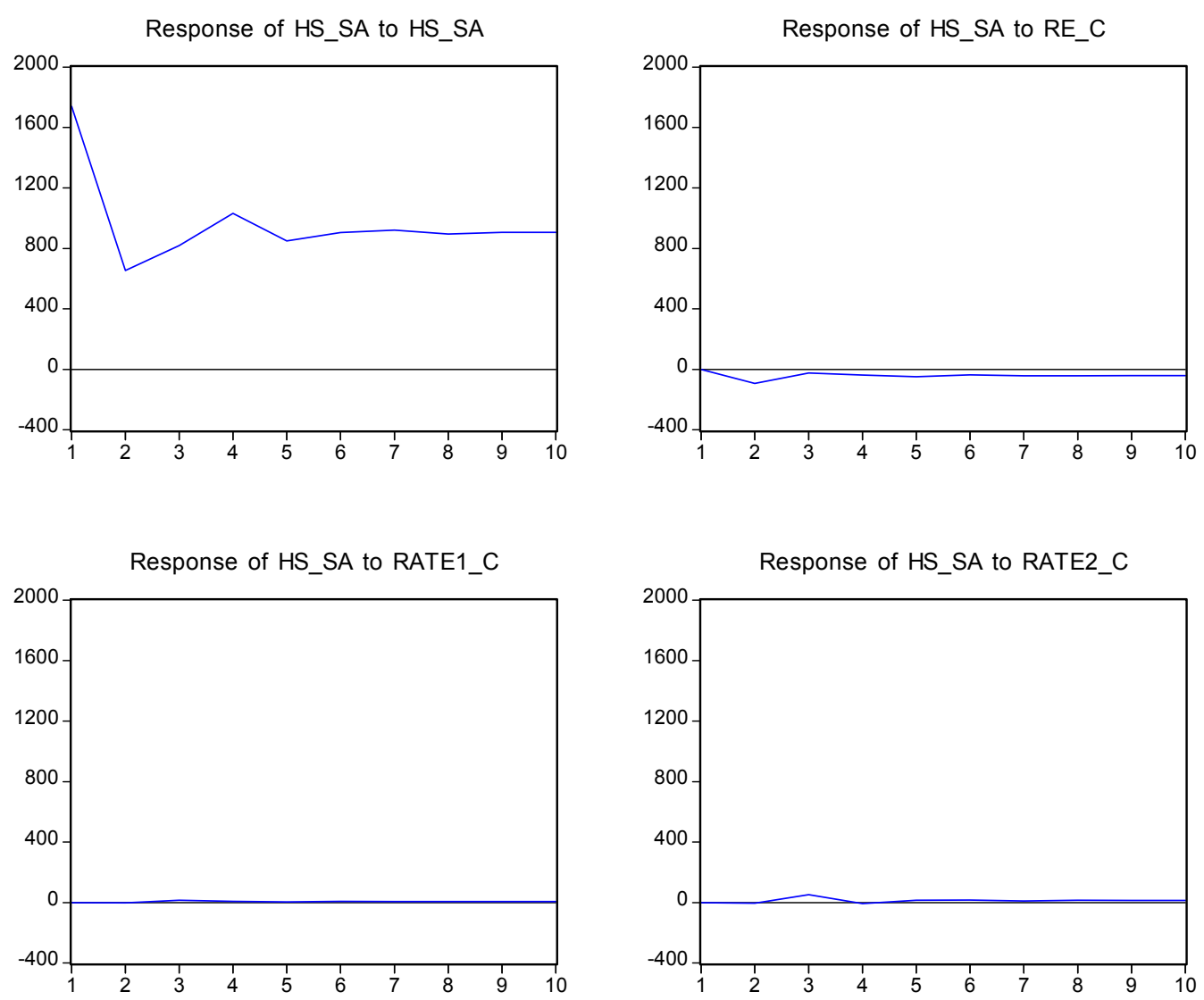

Figure 1. Response for Acreage of Property Sales Index to one variable

Response to Cholesky One S.D. Innovations \pm 2 S.E.
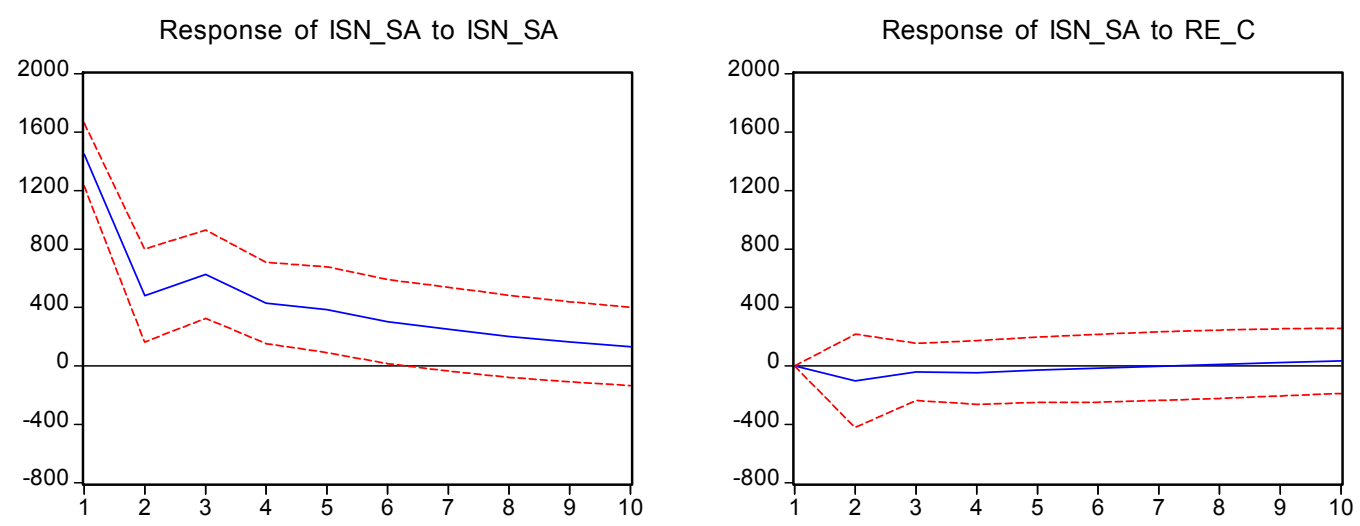

Figure 2. Response for Newly Started Acreage of Real Estate Index to one variable 